Europe's Journal of Psychology 3/2009, pp. 25-44

www.ejop.org

\title{
Qualitative Approach to Clinical Psychology. Explorative Studies
}

Lara Tagliapietra

Psychoterapist

Tatiana Alina Trifan

University of Padua

Laura Raineri

University of Padua

Adriana Lis (coord.)

University of Padua

Abstract

This article is aimed to present a new approach to clinical research and also to clinical work based on Grounded Theory and on the software developed from it, Atlas.ti. It includes two practical applications of this software, one is the analysis of a clinical interview and the other the assessment of nine interviews taken with the Five Minutes Speech Sample belonging to five couples of parents. As it is presented below, each analysis was performed as a circular process, starting from the data, grouping them into categories, creating codes and then returning to the data in order to sustain them and to establish relations between them. In our view, this is a new and interesting way of approaching clinical data which gives the clinician the possibility of developing a deeper understanding of the patient/client without loosing himelf/herself in the theories of the psychological orientation the psychotherapist belongs to.

Keywords - Grounded Theory, Five Minutes Speech Sample, clinical psychology, Atlas.ti, qualitative research, clinical psychology 
"We are not trying to generalize but rather to specify. We specify the conditions in which our phenomena exist, the actions/interactions that they concern and the associated results and their consequences. This means that our theoretical formulations are applied to these situations or circumstances and not to others. When we change the conditions, then the theoretical formulation should also change in order to adjust itself to the new conditions. The goal of a grounded theory should be always kept in mind."

Strass and Corbin, 1990, p. 191

Introduction

"Every human being is building a model of the world based on a combination of genetically determined factors and the personal experience. A "model" comprises all the experiences, all the generalizations corresponding to the experiences and all the rules that govern the generalizations. [...] There are not two identical models of the world." (Gordon, D., 1992).

The person we have in front of us is narrating herself and is representing what is said to her based on her own experience. Generally we try to organize all the types of input we receive (sensorial, perceptive, cognitive, etc.) in such a manner that they acquire a significance for us in order to be able to use them later. In other words, each of us has a subjective representation of reality based on which we process and filter the inputs that arrive to us form this reality. The way in which a person perceives and makes representations (symbolizes) of the stimuli is related to this subjective process of selecting information from the environment (material, social, etc.). This is a process that selects the data that corresponds to or confirms our needs and our experiences, more or less pleasant, and at the same time blocks the entrance in the consciousness of the information perceived as threatening for the Self.

This universal inclination, to appropriate ourselves of the world based on subjective schemes, is revealed through language. The way in which we speak and mostly the way in which we organize our speech (how we speak) is a lent that reveals our unique point of view, of which we are not always aware (Wittgenstein, 1953). 
In light of the previous assertions it is obvious that we cannot reduce the person to the symptom, because every person perceives and lives a certain discomfort differently, based on his/her own experiences and resources.

It is a common idea among psychologists that is more important not what a person says, but how she says it (Reich, 1958; Jefferson, 1973). For example, if for a person the expression "feeling bad" may mean a physical sufferance, for another may mean sadness, for another depression, etc. The discomfort, actually, is symbolized differently, depending on the person that experiences it.

For this, when one speaks about clinical report, it is worth analyzing also the way in which the patient/client organizes his speech.

If we are not able to catch the true significance the patient gives to his/her discomfort, to listen to him/her without preconceived ideas, then we will engage ourselves for sure in a deaf dialogue without any real benefit for both sides.

In order to reach such an objective, in the pshychoterapeutical environment we can avail our self of the ideas confirmed by Grounded Theory. Following such a thinking logic actually is possible to stress some key-words or codes of the patient's speech and later to establish cause-effect relations between them.

The relations that emerge in this way will help us understand how the patient perceives his discomfort, how he lives it and how he relates it with his personal history. In other words, it helps us create a mental map of the discomfort perceived by the person. This is a scheme useful for the psychotherapist in order to create an adequate image of the person, to make intervention hypothesis and which takes into account not only what the patient says, but "how he says it".

Often it is not the event that generates the trauma, but the significant that we assign to it. This is why what for a person has the subjective significant of a big trauma, for another is just an easy surpassable event.

\section{Grounded Theory}

Within scientific research there is always a strong debate between those that prefer quantitative methods and those who prefer qualitative ones. The first ones are those that have built the standards in experimental research and in researches performed on a large number of subjects and which use sampling 
criteria and statistical analysis techniques. On the other side, the qualitative method uses procedures of qualitative nature both at the level of collecting the data as well as the level of analyzing them. The gathering data procedures include: interviews, group discussions, observations, journals; while the analysis procedures include coding, categorizations and systematic confrontation between the categories and their dimensions. Such research is often defined as an explorative one, opposite to "classical" scientific research aiming to confirm / disconfirm initial hypothesis.

Among the qualitative methods used in the scientific research we can list: Focus Group, Speech Analysis, Conversation Analysis, Grounded Theory and Phenomenological Interpretative Analysis.

One of the frequently used and recognized methods in the academic environment is the method called Grounded Theory. This method was developed inside the sociological environment from the collaboration between Glaser and Strauss which have "discovered" it during a study on the awareness of death (Glaser e Strauss, 1967). In their work these authors have emphasized how, in the past, research was performed in an environment artificially separated from the daily clinical practice and how such artificiality depended on the separation between the data collection phase and the data analysis phase. Glaser and Strauss have proved that sociological and psychological theories can base themselves on qualitative data and that such data should not be seen just as a support to the quantitative data.

The connection between qualitative and quantitative methods can be understood in different ways: from some points of view, these methods are alternative and opposed, while from other points of view these are compatible and even complementary (Mantovani, 2003).

Glaser and Strauss intended to create a method which would allow them to go from data to theory, so that theory would emerge from the data in the purest intuitive way. The theories should emerge during research and should be read within the data they were grounded in. The methodology suggested by Grounded Theory allows a wider and more accurate data collection and also coding in categories which, differently from the traditional content analysis, are neither predefined nor mutually exclusive. The categories are identified through a coding process which in the initial phases of the research is mostly descriptive; with the advancement of the research, which emerges little by little from the 
data, the researcher produces codes from categories based on the data and on the context, categories which are not "borrowed" from the pre-existing theories of the research environment.

What seems like a "discovery" is in reality the result of the researcher's activity of mutual influence between the data and the conceptualization emerging little by little, the data collecting and the analysis not being separate, but interconnected. The relationship between theory and data cannot be solved in the favour of one or the other. A characteristic element of Grounded Theory is, actually, the "circular" conception of the research process. Such circularity leads the researcher reflecting continuously on the research process and on the single phases in the light of all the others.

The data analysis happens mainly through a process defined as "coding" which consists in individualizing a significance or a conceptual category inside the complex of data which is closer to the subject's own words. Confronting the various conceptual categories, one is able to extract a more general significance starting from the established categories and which can be a base for explaining the examined phenomena. Such process should happen through a circular path and not an inductive one. Little by little, through the coding, new hypothesis are formulated.

It appears clearly how, in this process, the interpretative act of the researcher becomes explicit. The researcher, working rigorously and systematically, codes and translates into categories the words of the subjects.

\section{Atlas-Ti}

ATLAS-TI is a software for qualitative analysis developed in Germany by Thomas Muhr in the mid-90's. This program is based to certain extent on Grounded Theory because of the flexibility of its operational modalities and the capacity to generate theories through the interaction between the researcher and the data.

The program offers instruments for visualising the characteristics and the relations between the data without loosing the complex direction and meanings of the research. Moreover, it facilitates an intuitive and creative approach to the data, assuring in the same time a certain systematisation of the research. 
Atlas was programmed to facilitate the development of a theoretical model firmly founded on the text, meaning that it produces scientific knowledge putting in interaction the researcher's analysis categories with the significances constructed by the subjects during their speech. The network structure of the program recalls the usage of interconnection which is based on Grounded Theory.

This is a very versatile program which allows you to make progresses in your research while advancing on different paths according to the research objectives established from time to time by the researcher. It allows the researcher to follow a path closed to that of the "pencil and paper" method, but with the advantage of making all the operations very fast and systematic and also allows an immediate interface for the data visualization.

The operations one needs to perform in order to work with ATLAS are: the creation of hermeneutic units, coding the material, analysis of the relations between the codes and the visualization of the conceptual maps. Once the coding is performed, Atlas facilitates the formal organization of the data which make easier the operations of synthesising the results. It is also easy to recuperate the quotations from the text and to compare them. With the help of graphic outputs and the creation of networks one can easily organize and visualize the data according to the research goals, or, for the analysis, to create mental maps in order to illustrate theoretical development.

Muhr resumes the logic of Atlas in his so-called vise principle: visualization, integration, serendipity and exploration. The program allows actually to visualize the property of the objects and their relations (Visualization), to not lose sight of the global significance of the texts while working on specific levels (Integration) and to maintain an intuitive and innovative approach of the texts (Serendipity and Exploration).

\section{Possible Practical Applications}

Analysis of a clinical interview

In these pages we are going to present the analysis of a clinical interview done with the help of the Atlas-Ti software.

All the codes have been extracted from the speech of the patient and correspond to the exact words pronounced by the patient, while the relations 
between the codes were created taking into consideration the order in which they appeared throughout the interview.

In the quoted example we can find as the central nucleus of the patient's discomfort in the depressive cycle:

\section{Iniziativa - Rinuncia/Rifiuto - Delusione - Sentimenti Depressivi \\ Initiative - Renunciation/Refuse - Disappointment - Depressive Feelings}

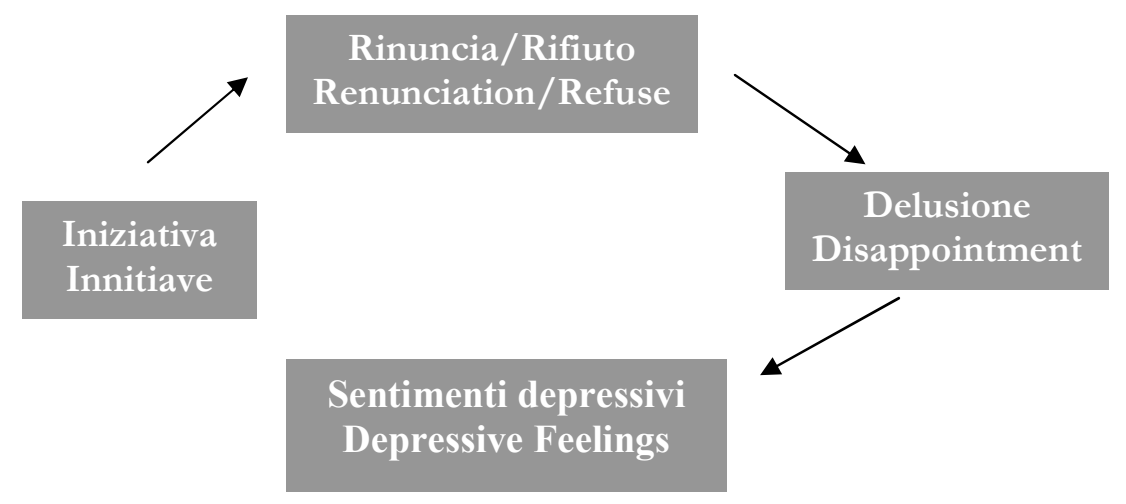

Such central nucleus is composed of more specific components which represent the "false believes" of the patient and which condition the way in which s/he observes and relates with the surrounding environment.

In the analyzed interview, actually, the speech of the patient is organized around the expression of the following needs and affective states:

* the need to have someone beside (usually associated with their own beliefs), connected with * the fear of being abandoned and with * the fear of not being disappointed, which generate ${ }^{*}$ distrust of others (associated with ruminations); this distrust leads to * the tendency to distance oneself from other people when one thinks he/she is being judged, which generates the * relating difficulties and, implicitly, fuels the * panic generated by being abandoned without explanation.

Together with the * feeling of discomfort in interacting with the others, these lead to the isolation, as part of the depressive cycle (Beck's depression triad includes isolation as attitude that fuels the collapse into depression). 
Beck's triad (DEPRESSION- ISOLATION- SOCIAL REFUSAL- INCREASING DEPRESSION) can be presented in this case as a mix of feelings such as disappointment, dysphoria, anger and discomfort.

The analysis of how the patient organizes his/her speech helps us formulate diagnostic hypothesis about his/her sufferance without losing sight of the subjective significance s/he gives to such a pain. Every discomfort, actually, although called the same, as, for example, depression, can have a completely different significant in the context of different personalities.

An analysis performed in this way allows us to capture the situations that are "causing" the depressive feeling inside the patient, and, at the same time, reveals the mental schemes on which these feelings arise.

The first graphic makes a resume of the mental map of the depressive disorder of the patient. 
Graphic 1: Mental Map of the Patient's Discomfort

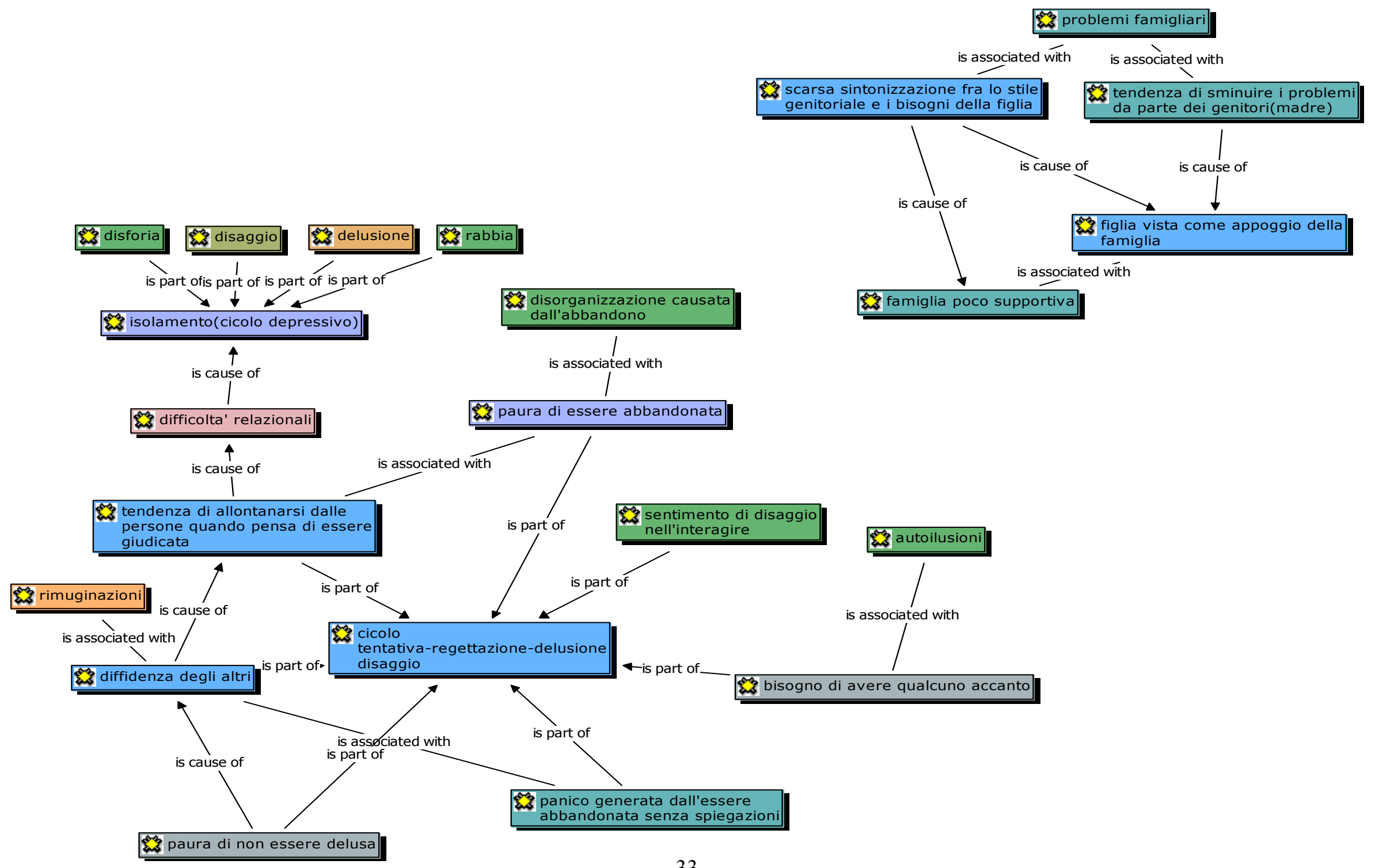


Analysis of the Five Minutes Speech Interviews through Atlas-Ti

Introduction

In the field of text analysis, Atlas.Ti appears as an extremely useful and versatile software created especially with the goal of making easier the qualitative investigation of the contents that constitute the research object. Especially, the program, exactly for the network model on which it is based, facilitates the organization of the data and the synthesis of the results based on the guidelines established by the researcher.

Goal

Assessing 9 Five Minutes Speech interviews belonging to 5 couples of parents (in one of these couples the father was deceased) through the Atlas-ti software.

Sample description:

$\begin{array}{lllllll}\text { Family } & \text { Child's gender } & \text { Marital situation } & \begin{array}{l}\text { Age } \\ \text { Mother }\end{array} & \begin{array}{l}\text { Work } \\ \text { Mother }\end{array} & \text { Child's age } & \begin{array}{l}\mathbf{N}^{\circ} \\ \text { sons }\end{array} \\ \text { F } & \text { F } & \text { Married } & 37 & \text { Civil servant } & 6 \text { years } & 2 \\ \text { C1 } & M & \text { Married } & 43 & \text { Collaboration } & 4 \text { years } & 3 \\ \text { C2 } & \text { F } & \text { Married } & 38 & \text { Agriculture } & 5 \text { years } 1 \text { month } & 2 \\ \text { M } & \text { F } & \text { Married } & 35 & \text { Nurse } & 4 \text { years } 1 \text { month } & 2 \\ \text { D } & \text { M } & \text { widow } & 45 & \text { House wife } & 4 \text { years } 7 \text { moths } & 1\end{array}$

The reading of the interviews with the help of this software makes immediately visible the distribution of the variables, coded with the help of the Five minutes speech, for the 5 couples of parents analysed, as represented in Table 1.

$\underline{\text { Table } 1}$

\begin{tabular}{|c|c|}
\hline ------ & IMARY DOCS \\
\hline CODES & 1223456678 9 Totals \\
\hline - & (-) \\
\hline Initial ne & 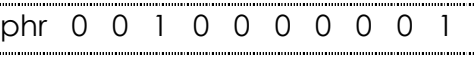 \\
\hline
\end{tabular}




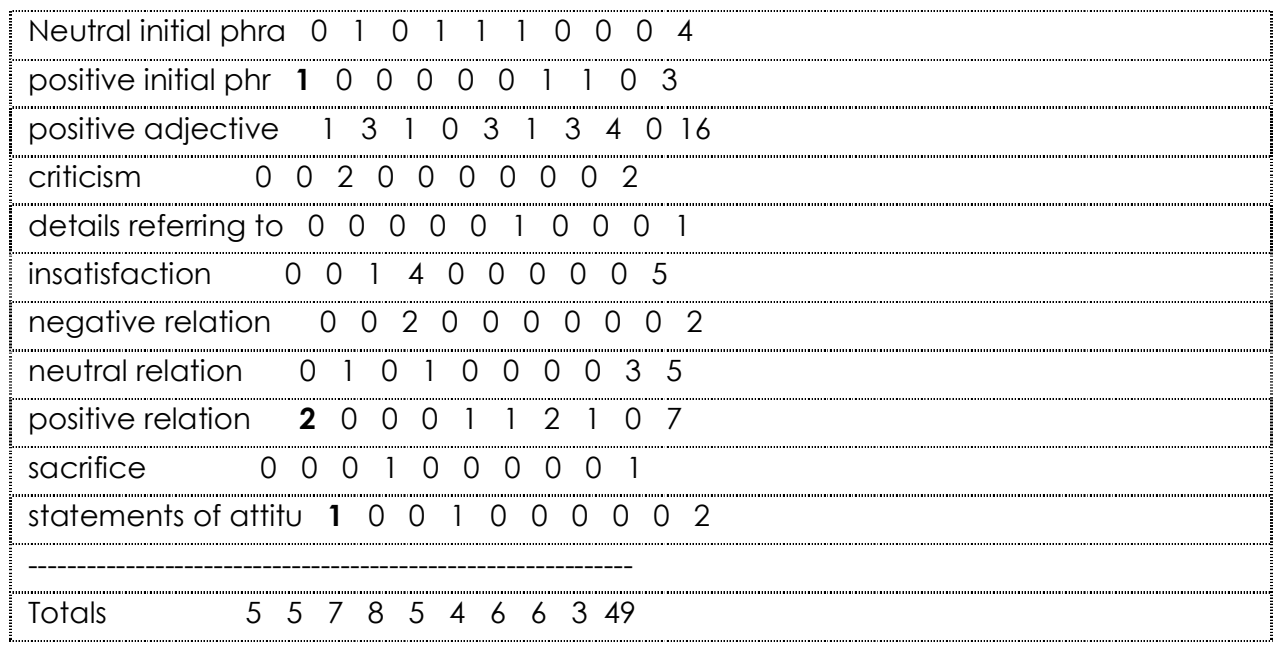

For example, the first subject is distinguishing himself by:

A positive initial phrase

A positive adjective

Positive relations

Statements of attitude.

This type of coding makes the subject fell into the macro-category defined as "low expressed emotion".

The same reading can be done for the other 9 subjects.

The next step was that of creating outputs that allowed us an immediate reading of the expressions (codes) in order to make the difference between high expressed emotion and low expressed emotion, like in the examples that follow. The various codes presented in Table 2 indicate the position of the phrase inside the text: for example, the phrase "our relationship is a good one" was said by the first subject $(\mathrm{P} 1)$ in the second sentence of the speech $(1: 2)$.

Table 2:

Subject 1:P 1: MAMMA-F
P 1: 1:1 (4:4)
Codes: [frase iniziale positive - initial positive phrase]
è molto... è simpatico - she is very ... she is funny
P 1: 1:2(11:11)




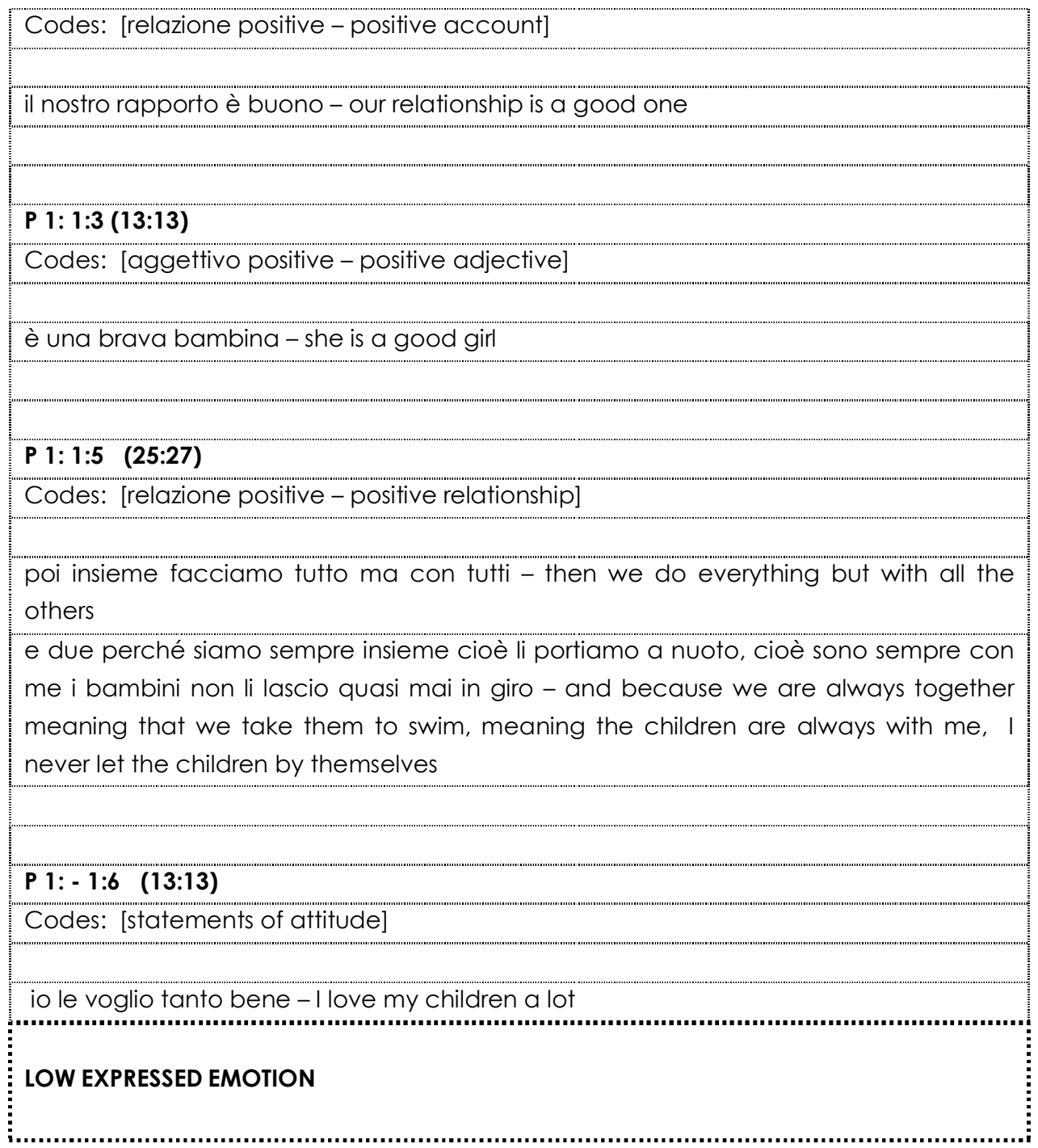

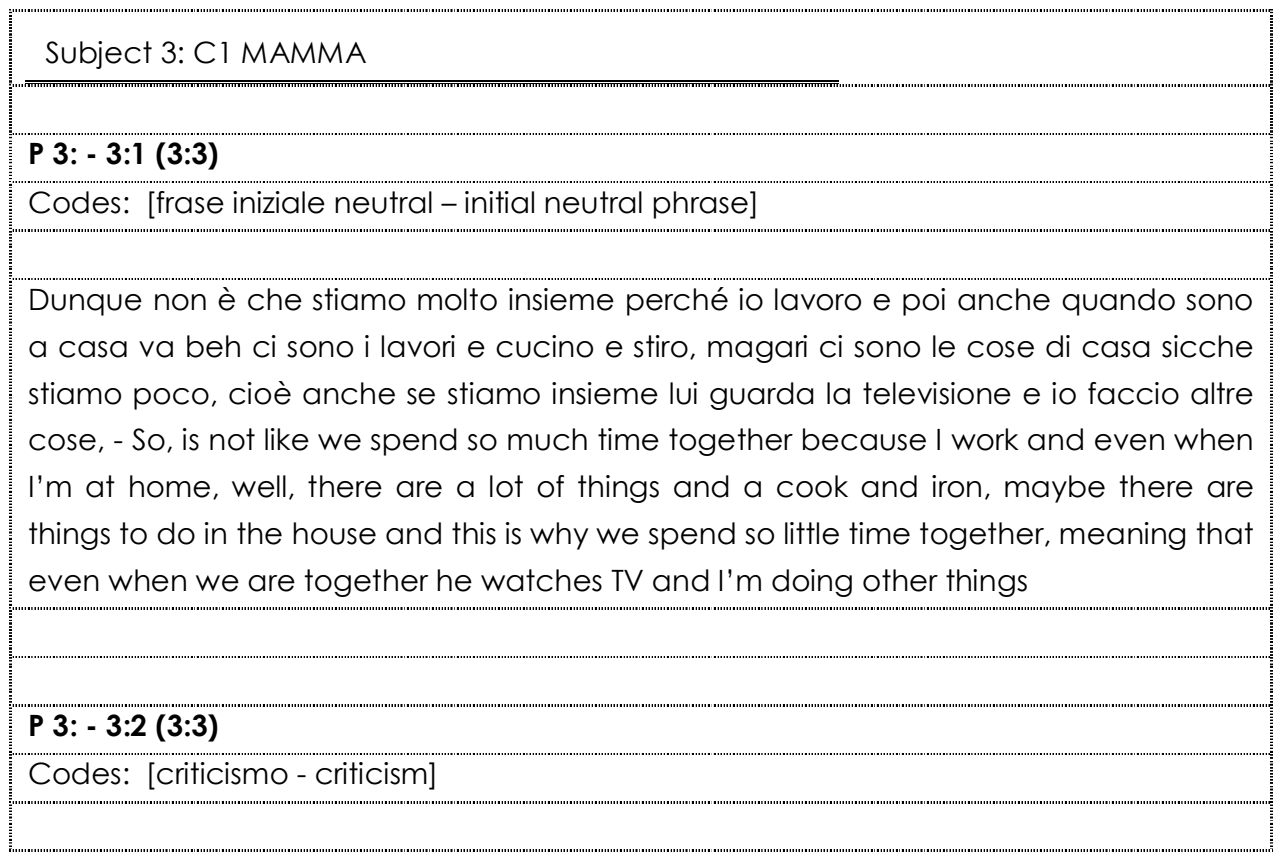




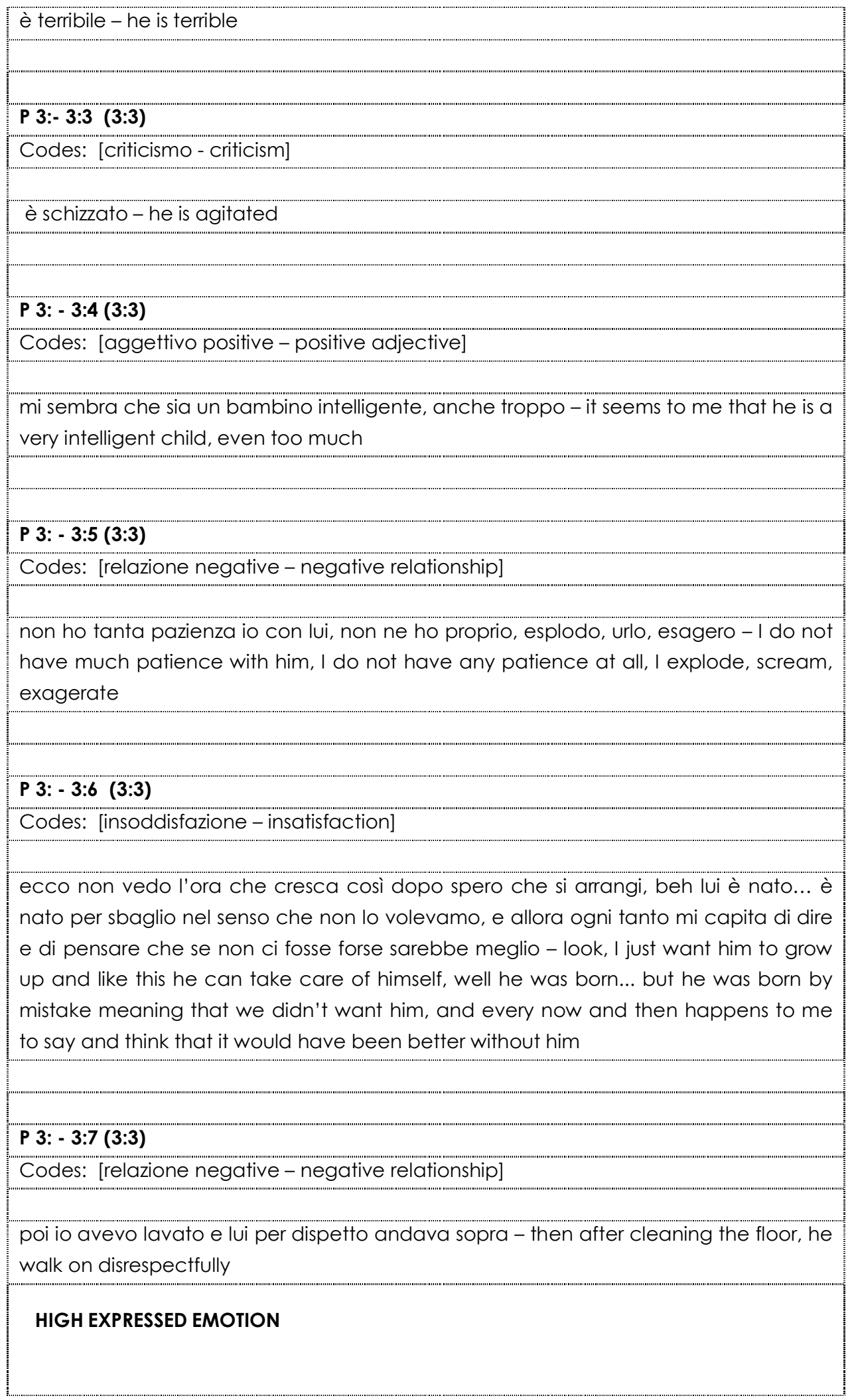

Table 3 reproduces, through graphs, the "quotations" or better said the expressions with which the mothers belonging to the two macro-categories, "HIGH EXPRESSED EMOTION" and "LOW EXPRESSED EMOTION", have described 
their child. At the same time, for each mother the presence and the quality of variables coded by the "FIVE" interview (initial phrase; relation; adjectives; etc.) is visible. Given the small sample used for the study, only one mother enters the macro-category "HIGH EXPRESSED EMOTION".

The first graphic shows that, when speaking about her own child, this mother tends to use mostly negative descriptions. Actually, throughout the discourse, feelings of insatisfaction and devaluating representations prevail and these interweave with difficult relationships.

This is the case of an unwanted child, born in an adult couple that has older children. The qualitative analysis of the text shows clearly the difficulties the mother has in understanding the behaviour of her own child, described as "terrible", "agitated", a child that, "if one doesn't give him what he asks, goes out of his mind", therefore with a low tolerance to frustration.

The experienced discomfort is so powerful that this mother is induced to think that "it would have been better without him". These are very aggressive thoughts that can urge feelings of guilt.

This type of narration in its complexity reveals the severe difficulties present in the relationship between this mother and her son. This is a high risk situation, which may be helped through interventions oriented toward the sustainment both of the mother in her parenting role and of the child in his development.

The analysis of the organization of the speech points out the incoherencies in the mother's description of her child. She starts speaking neutrally about him, (*neutral account), continues with severe devaluations (*criticism), and arrives at employing a positive adjective which is cancelled by an ulterior devaluation. This extreme variability in the way of narrating about her son emphasizes the fragility and the lake of stability of the maternal representation. In her speech, the negative aspects actually prevail. The interview ends with other devaluations both of the relationship with her son and of her maternal experience.

This type of assessment is in agreement with the assertions of the literature in the field that states that patients living in "HIGH EE" environments are at a higher risk of developing psychiatric disorders (Humbeeck, Audenhove, Hert, Pieters e Storms, 2002) comparatively with patients coming from a "LOW EE" environment. 
The second graphic shows the expressions used by the mothers belonging to the "LOW EXPRESSED EMOTION" category. When confronted with the previous graphic, one can see the diversity with which these mothers tend to describe their own child.

There are missing, actually, in their sentences, the negative and devaluating terms, while the positive adjectives prevail, as: "brave", "attentive", "really good girl" and the kind accounts.

As for the previous narration, the resulting familiar environment is a serene one, with a major reciprocity in the mother-son dyad and with an adequate emotional atmosphere.

We've granted a special attention to the family in which the father is missing, represented with the help of ATLAS.ti in the third graphic.

The mother relates her relationship with her own child using exclusively neutral terms, lacking that special warmth that is specific to the mother-son relation. This mother-son couple seems frozen in the experience of mourning the father's death. The emotions seem isolated as a defence and the words are cleared from any recall to feelings, maybe because these are too painful to bear. The only emotion that is allowed to exist is a depressive one and refers exactly to the mourning, as it emerges from the mother's words:

"Yes, before I saw him happier, saying the truth, this when his father lived. Silence. Something is missing, and it's normal, it is not as it used to be and I am aware of it, I do not know myself what to do, sometimes a friend of his comes and they play together and he cares about him, he has the same age as V., and in those moments I see him a bit happier. Yes, he is ok while with me, but something is missing, yes."

If we analyse "how" this mother narrates about her child, the poverty of her style drags our attention. Comparatively with other mothers she uses both few words and few evaluations of her relationship with her son. Even more, her evaluations are lacking affectivity. She starts her speech using initially a neutral phrase and finishes it with another neutral one. 


\section{$\underline{\text { Table } 3}$}

Graphic 1: High Expressed Emotion

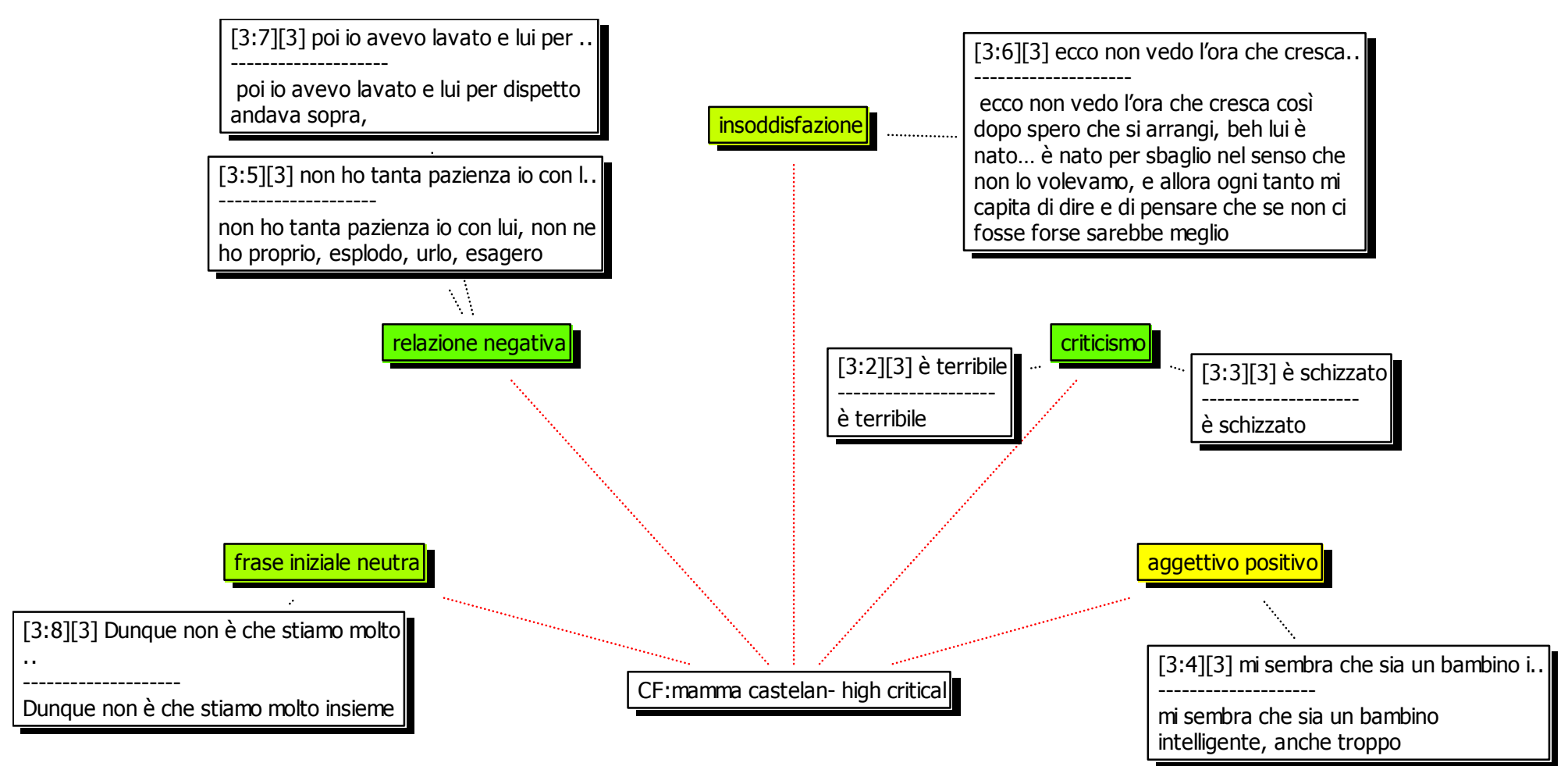


Graphic 2: Low Expressed Emotion

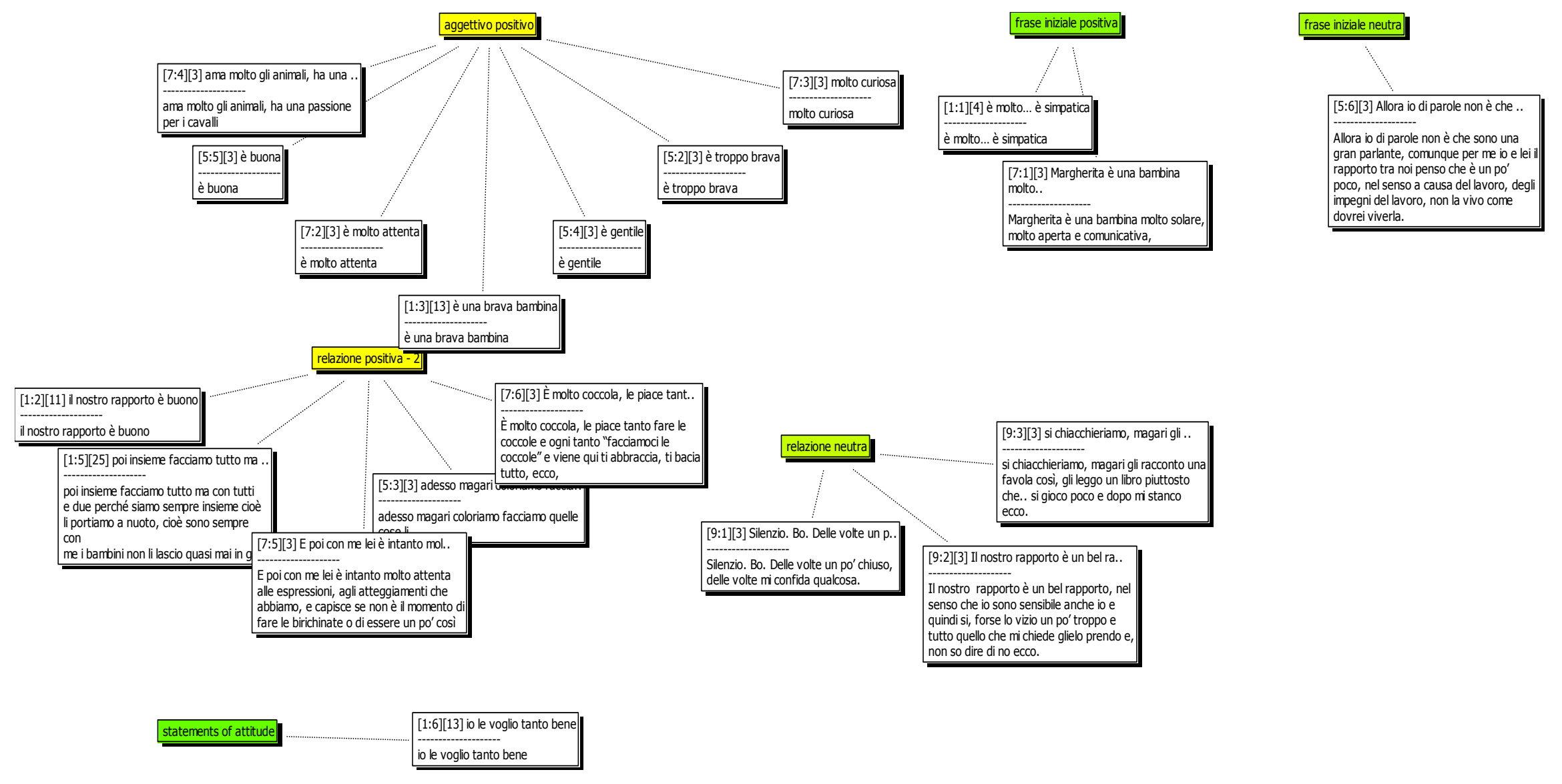


Graphic 3:

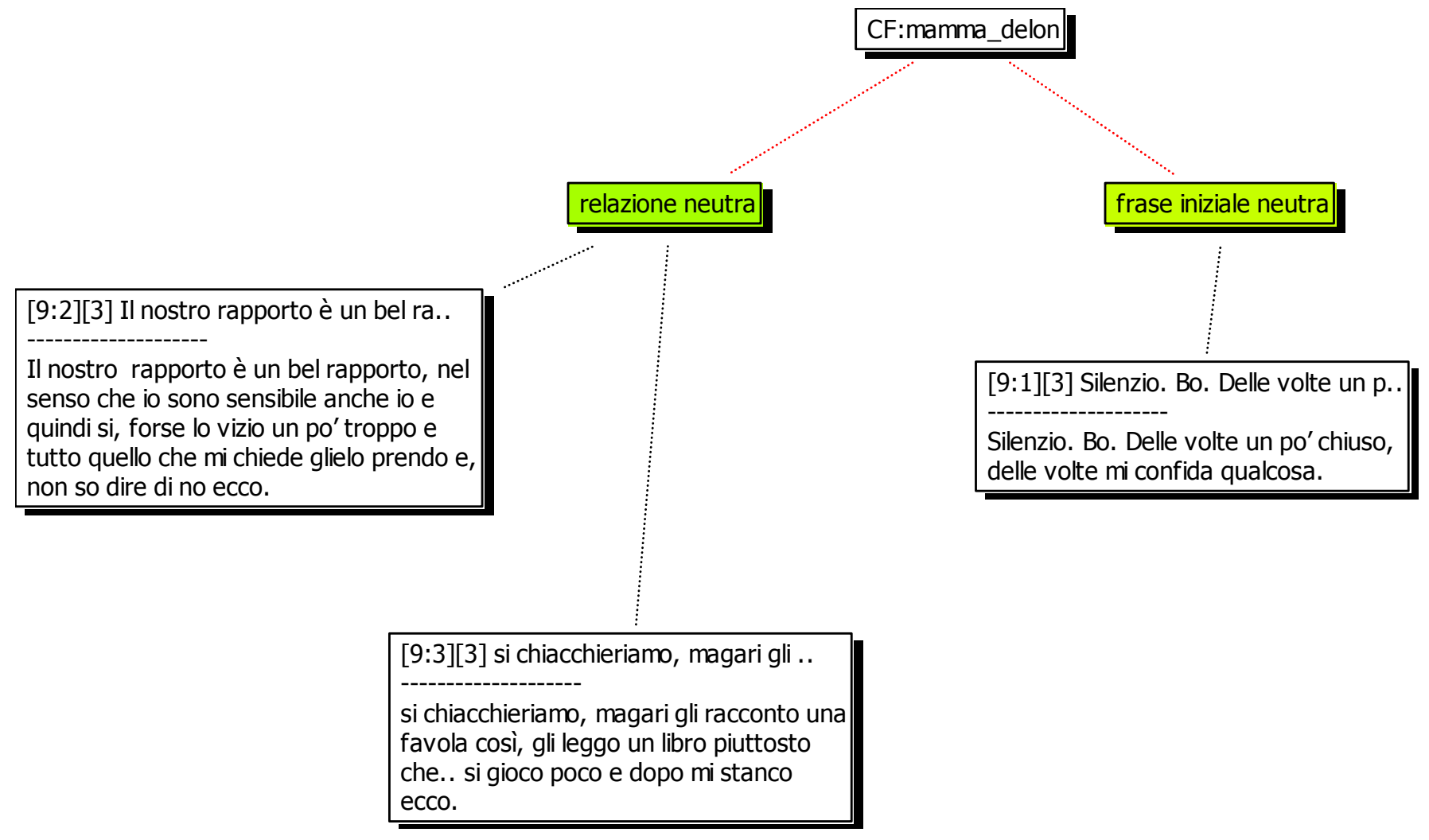


Conclusions and possible follow-ups

As one can see, this software helped us to build a coherent representation of the key-elements that emerged from our analysis.

The same process can be performed on the fathers' interviews and then compare them with the mothers' FIVEs, or, by taking into consideration other variables, such as the age of the parents, the presence of siblings, etc. And this program can be also used for other goals related to the parental representation, if we stay centred just on this instrument (FIVE).

These techniques can be used not only for the analysis of this particular instrument we have chosen for the current presentation, but also for many other instruments that require a rather qualitative approach.

\section{References}

Mantovani, G., Spagnolli, A. (2003): Metodi qualitativi in psicologia. Bologna, II Mulino

Van Humbeeck, G., Van Audenhove Ch., Pieters, G., De Hert, M. Storms, G. (2002). Expressed Emotion: a review of assessment instruments. Clinical Psychology Review, 22

Glaser, B. D. (1978). Advances in the methodology of Grounded Theory: Theoretical sensitivity. Mill Valley, California: Sociology Press.

Glaser, B., \& Strauss, A. (1967). The discovery of Grounded Theory: strategies for qualitative research. New York: Aldine de Gruyter.

Gordon, D. (1992), Metafore terapeutiche, Astrolabio, Roma

Strauss, Anselm/ Corbin, Juliet (1990): Basics of Qualitative Research. Grounded TheoryProcedures and Techniques. (Sage Publ., Part I), Newbury Park., page 191

About the authors:

\section{Lara Tagliapietra}

She is a psychotherapist specialized in child's psychology. Over the years she had multiple collaborations both with public and with private entities on psychological 
assessment and support. She also teaches psychodiagnosis and psycholinguistic classes. From children's assessment to adolescents' emotional education, she had shown a keen interest in finding new approaches that will improve her pasychotherapeutical work.

\section{Laura Raineri}

She has a BA on Psychological Sciences of the Personality and Interpersonal Relationships (2006) and a specialization in Clinical Psychology - Psychodynamic approach (2008). Presently she is finishing her apprenticeship at the University of Padua, Italy, Faculty of Psychology, participating at the sessions of the S.A.P. sessions (psychological assistance for students), to the Selma Freiberg Laboratory and to various research projects and from September she will attend the Mara Selvini Palazzoli School of Systemic Psychotherapy. During the years she has attended various training courses on psychodiagnostic instruments (WISC, WAIS, ORT, RORSCHACH EXNER, TAT, CAT, etc.) and has also participated to conferences and seminars regarding children and family assessment. She had also made developments on the CAT assessment and currently is working with processing instruments (Atlas.ti, Spad.t), trying to improve the clinical assessment through qualitative instruments.

\section{Tatiana Alina Trifan}

She has a BA on Psychology (2005) at the University of Bucharest, Romania, Faculty of Psychology and Educational Sciences, a MA in Cognitive-Behavioural Therapies at the Titu Maiorescu University (2007), Faculty of Psychology and a predoctorat (2nd level Master) in clinical psychotherapy and psychodiagnosis (psychodynamic approach) (2008) at the University of Padua, Italy. She has performed researches both in the clinical and in the organizational field, with traditional psychodianostic instruments as well as with modern ones, showing a keen interest in the complementarity between qualitative and the quantitative approach. She has various training courses on psychodiagnostic instruments (WISC, WAIS, RORSCHACH EXNER, ORT, TAT, CAT, etc.) and during her work within the field of drug addiction she had developed an instrument that combines both the qualitative aspects and the quantitative ones. From January till June 2010 she has obtained a free-research grant on the assessment and support for the people diagnosed with psychosomatic disorders. 